\title{
Promessas antológicas: o conto latino-americano contemporâneo a partir de algumas antologias
}

Wilson Alves-Bezerra*

\author{
¿Dónde está la memoria de los días \\ que fueron tuyos en la tierra, y tejieron \\ dicha y dolor y fueron para ti el universo? \\ El río numerable de los años \\ los ha perdido; eres una palabra en un índice. \\ Jorge Luis Borges (1992, p. 272)
}

As antologias, como as listas em geral, costumam ser reveladoras. Quem se dedica ao exercício da seleção teve necessariamente de abrir mão da volúpia pela totalidade, ainda que deva - de alguma forma - fazer a defesa da unidade e dos bons critérios. Daí seus prefácios serem verdadeiros exercícios de estilo e persuasão.

As literaturas americanas, no segundo semestre de 2010, foram objeto de ao menos três importantes antologias de autores contemporâneos. A coincidência editorial se faz mais reveladora ao se perceber que não há um só autor que frequente as três seleções, e que há apenas um que aparece em mais de uma delas - trata-se de Edmundo Paz Soldán. Apesar dos diferentes critérios, a disparidade é reveladora da ausência de um corpus canônico, por mínimo que seja.

As duas coletâneas lançadas no mercado brasileiro contrapõem-se quanto a seu alcance: há uma panamericana, organizada por um francês e publicada no Brasil; outra exclusivamente de literatura argentina e também publicada em português; e finalmente uma terceira, lançada no mercado francês e organizada por um venezuelano. Os três escopos diversos das publicações antes de ser motivo que desautorize uma análise comparativa entre elas, auxiliam na evidenciação dos recortes moventes e na não coincidência entre a escolha de territórios de observação. Tal como inexiste um corpus de autores contemporâneos canônicos, tampouco há coincidência no estabelecimento de limites literários e linguísticos e de um território. Isto se nota por um certo esvaziamento de categorias consagradas no século XX como 'panamericano', 'latino-americano' e mesmo 'argentino', como veremos nos prefácios dos organizadores de cada obra.

\footnotetext{
* Tradutor, crítico literário e Professor Adjunto do Departamento de Letras da UFSCar. Doutor em Literatura Comparada pela Universidade Estadual do Rio de Janeiro (UERJ).

E-mail: wilson_alves@yahoo.com.
} 
A Antologia pan-americana (2010), organizada pelo agente literário francês Stéphane Chao, tem pretensões continentais, ao recopilar autores consagrados e iniciantes, de língua portuguesa, espanhola, inglesa e francesa, com contos produzidos ao longo dos anos 1990 e 2000. É um amplo espectro que passa por nomes de lugar já sedimentado nas letras latinoamericanas, como os recém-falecidos Juan José Saer e Mario Benedetti, e outros mais jovens, como Edmundo Paz Soldán. O espaço aos brasileiros é amplo, e nele cabem Luiz Ruffato, Marçal Aquino e Raimundo Carrero'. $\mathrm{O}$ organizador parece atender a muitas das expectativas que se podem nutrir em se tratando de uma publicação como esta: opta pela inclusão de textos antológicos, textos menores que produzem sorrisos condescendentes e textos de autores promissores. Nota-se a ausência de pretensões definidoras do que é o "panamericano", que termina servindo como um pretexto para poder apresentar autores de diversos países e línguas.

Já Os outros: antologia de narrativa argentina contemporânea, organizada pelo escritor e psicanalista argentino Luis Gusmán (2010), é quase uma antiantologia, com a piscadela que o título traz ao leitor: de uma antologia argentina, o leitor poderia esperar mais pelos "uns" (Jorge Luis Borges, Julio Cortázar, Ricardo Piglia, Rodolfo Walsh, Juan José Saer, Roberto Arlt e Horacio Quiroga), que pelos "outros", mas Gusmán ousa e traça um mapa diverso, que inclui Anna Kazumi Stahl, uma nipônica nascida nos Estados Unidos que adotou a Argentina como país e o espanhol como idioma de sua escrita literária; e outros nomes bem pouco conhecidos dos brasileiros, como o já falecido tradutor do Finnegans Wake, Carlos Eduardo Feiling; e Luis Tedesco, um septuagenário que escreve poemas em prosa com rara felicidade. Isto porque o termo antologia, nas palavras de Gusmán, "quer dizer diferença, não soma" ${ }^{2}$. Como veremos adiante, embora seja uma antologia nacional, o mapa de contornos definidos fica esmaecido pela entrada de autores estrangeiros, e pelo signo da dispersão.

\footnotetext{
${ }^{1}$ A lista completa dos autores selecionados dá uma ideia do quão amplo é o espectro adotado pelo organizador: Abdón Ubidia, Alberto Mussa, Alonso Cueto, Amilcar Bettega, Ana Teresa Torres, André de Leones, André Paradis, Dany Laferrière, David Toscana, Delfina Acosta, Edmundo Paz Soldán, Eduardo Berti, Edwige Danticat, Edyr Augusto, Ellen Ombre, Eloi Yagüe Jarque, Enrique Jaramillo Levi, Ernest Pépin, Frank Martinus Arion, Horacio Castellanos Moya, Jonathan Safran Foer, Jorge Franco, José Acosta, José Manuel Prieto, Juan José Saer, Junot Díaz, Luis López Nieves, Luis Sepúlveda, Luiz Ruffato, Margaret Atwood, Mario Benedetti, Marçal Aquino, Miguel Sanches Neto, Olive Senior, Rabindranath Maharaj, Raimundo Carrero, Raywat Deonandan, Richard Ford, Ronald Flores, Ronaldo Correia de Brito, Sherman Alexie, Steven Milhauser, Sylvain Trudel, Sérgio Ramírez, Zee Edgell.

${ }^{2}$ Os escritores selecionados por Gusmán são: María Moreno, Sergio Chejfec, Luis Tedesco, Carlos Eduardo Feiling, Antonio Oviedo, María Martoccia, Gustavo Ferreyra, Jorge Consiglio, Sergio
} 
Mas talvez seja Les bonnes nouvelles de l'Amérique latine (2010) o livro que suscite mais interesse à discussão aqui proposta, e ainda mais para o público brasileiro. Em primeiro lugar por não se dirigir aos brasileiros ou mesmo aos latino-americanos em geral; trata-se de um livro da série $\mathrm{Du}$ monde entier, dirigida ao leitor francês. Em segundo lugar, por ignorar o Brasil: entre os 32 autores do livro, não há um só brasileiro. Uma cartografia sui generis, para dizer o mínimo ${ }^{3}$. Soa estranho, depois de toda a reflexão dos anos 1970 que buscava considerar os diálogos culturais do território ao sul o Rio Bravo, este passo atrás. Desde a série da Unesco, $A$ América Latina em sua literatura, dirigida por Cesar Fernandez Moreno, até a obra do uruguaio Ángel Rama, havia esforços interessantes no sentido de pensar o continente de forma articulada.

A despeito do "sequestro" da literatura brasileira, cabe apontar que, no geral, a disparidade entre os autores selecionados indica sobretudo a dificuldade de traçar um panorama sobre a produção literária contemporânea. Um dos organizadores da edição da Gallimard, Gustavo Guerrero, num artigo de 2009, apoiava-se em critérios editoriais para sustentar tal hipótese: "ao crescimento exponencial da oferta de livros e à relativização dos critérios de julgamento, é preciso acrescentar a dispersão geográfica e a precariedade ou inexistência dos sistemas de distribuição em nível continental" (Guerrero, 2009) (tradução minha).

$\mathrm{O}$ argumento seguinte, embora seja introduzido como uma sorte de paráfrase do anterior, é de outra ordem:

os livros de autores latino-americanas não circulam ou circulam precariamente entre os países da região (...) o mexicano Jorge Volpi constata (...): “Os laços entre escritores e leitores latino-americanos - aponta em um artigo recente - são cada vez mais precários". E acrescenta em seguida: "Os leitores de cada país mal conhecem os escritores dos outros ("A literatura latino-americana não existe mais", Revista de la Universidad de México n. 31, México, 2006, p. 91). Hão de concordar comigo que, diante de indicações como es-

Bizzio, Flavia Costa, Juan Becerra, Guillermo Piro, Pablo Katchadjian, Ana Arzoumanian, Matías Serra Bradford, Mariano Fiszman, Daniel Guebel, Martín Kohan, Matilde Sánchez, Luis Chitarroni, Federico Jeanmaire, Anna Kazumi Stahl, Marcelo Cohen, Alan Pauls, Ricardo Zelarrayán, Florencia Abbate, Roberto Raschella.

${ }^{3}$ Os autores constantes da antologia francesa são: Guillermo Martínez, Andrea Maturana, Ronaldo Menéndez, Eduardo Antonio Parra, Edmundo Paz-Soldán, Juan Carlos Méndez Guédez, Jorge Eduardo Benavides, Guadalupe Nettel, Ignacio Padilla, Rodrigo Fresán, Juan Gabriel Vásquez, Álvaro Enrigue, María Fasce, Leonardo Valencia, Miguel Gomes, Andrés Neuman, Juan Carlos Chirinos, Eduardo Halfon, Karla Suárez, Jacinta Escudos, Rosa Beltrán, Claudia Amengual, Carlos Cortés, Alberto Fuguet, Mayra Santos-Febres, Gabriela Alemán, Aurora Arias, Claudia Ulloa Donoso, Ena 
Wilson Alves-Bezerra

tas, que chancelam o estado de mútua ignorância em que vivem os próprios latino-americanos, soçobra a ideia de que existe uma literatura latino-americana orgânica e integrada, e sofre ainda mais a premissa de que é possível elaborar com facilidade um panorama atual das letras do continente, sobretudo se se pretende executá-lo a partir do interior da América Latina. (id.) (tradução minha)

É preciso concordar que ambas asseverações de Guerrero são razoáveis: 1) a oferta de livros é cada vez maior na América Latina; 2) os latinoamericanos não se leem uns aos outros. No entanto, a ignorância mútua entre os latino-americanos não tem nada de novo: o escritor chileno José Donoso, em Historia personal del boom, ao revisitar suas memórias do boom da literatura latino-americana, fazia a mesma observação quanto aos anos 1950:

Borges, Carpentier, Onetti eram quase desconhecidos no Chile antes da década de 1960. (...) Ninguém sabia, em cada país, que coisas estavam sendo escritas nos outros países hispanoamericanos, sobretudo porque era tão difícil publicar e difundir um primeiro romance ou primeiro livro de contos. (...) O isolamento nos convencera de que esta situação era normal, a única possível. (Donoso, 1987 [1972], p. 24-5) (tradução minha)

De modo que a não-leitura recíproca parece ter sido a constante no continente, e ter-se suspendido justamente com o boom, ao menos no que tange aos autores "mundializados" naquela ocasião, que viriam a se tornar "o cânone latino-americano" ao olhar europeu4. O boom pode ser entendido como o momento em que, nas letras latino-americanas, produção literária e mercado editorial celebram seu matrimônio. De forma que a expressão "la relativización de los criterios de juicio" poderia ser lida como um desdobramento perverso daquele acontecimento.

É sintomático que no texto de Guerrero surja a pergunta sobre os bestsellers hispânicos, que ele recolhe da boca de Carlos Cortés: "Como situar autores de best-sellers como Paulo Coelho, Isabel Allende, Marcela Serrano ou Luis Sepúlveda no âmbito iberoamericano? Como inscrever a atualidade na tradição?" (Cortéz apud Guerrero, 2009, p. 25-6) (tradução minha). Causa estranheza diluir Coelho e Allende num relativismo perverso sob a etiqueta da "actualidad", e a partir daí afirmar que os critérios se tornaram relativos ${ }^{5}$. Como se o instrumental da reflexão literária se tivesse

\footnotetext{
${ }^{4} \mathrm{O}$ olhar europeu parece haver, de maneira geral, calcificado a literatura latino-americana no boom literário. O prêmio Nobel conferido a Mario Vargas Llosa pode ser entendido como um indício disso. ${ }^{5}$ Roberto Bolaño, para citar um exemplo de autor contemporâneo que não parece ter dificuldades de julgamento crítico, qualifica a obra dos best-sellers latino-americanos. No trecho a seguir, explica por
} 
suspendido por conta do aumento das cifras de venda. Não soa atinado que o advento do fenômeno mercadológico do best-seller tenha afetado o que se convencionou chamar o pensar e o fazer literário.

Afora isso, o texto de Guerrero, embora trate com precisão dos modos de produção, venda e distribuição dos livros, não se detém, por um momento sequer, na escrita literária. Sua reflexão é sobretudo editorial.

Tal discussão sobre o artigo de Guerrero, anterior à publicação da antologia em questão, serve-nos para iluminar, em grande medida e, de muitas formas, o modo de organização que norteou a coletânea por ele organizada no ano seguinte, em parceria com Fernando Iwasaki, Les bonnes nouvelles de l'Amérique latine. $\mathrm{O}$ argumento da porosidade e multiplicidade presente na produção contemporânea parece nortear a antologia, a começar pelos textos de apresentação. As "boas novas" ou "boas nouvelles" latino-americanas anunciadas têm em Mario Vargas Llosa, que então não era ainda o detentor do Nobel (o livro foi publicado em setembro), o seu mestre de cerimônias. Ele é o responsável pelo breve prefácio, em que proclama, à maneira de argumento final, a multiplicidade como definidora do volume: "América Latina é múltipla, e nada a exprime nem a define melhor que a boa literatura" (Guerrero e Iwasaki, 2010, p. 11) (tradução minha).

O trecho acima é o fechamento de sua tentativa de mapear a produção presente no livro. O critério da "boa literatura" que define a "América múltipla" é argumento final de seu texto, e parece demitir-se de qualquer tentativa de delimitação. Entretanto, é o que coroa os elementos comuns, por ele levantados, que unem os autores da antologia:

- não seguirem o realismo mágico;

- serem realistas em certa medida que já não é a mesma do início do século XX;

- não explorarem o pitoresco e a cor local, mas explorarem paisagens urbanas. ("A visão provinciana ficou definitivamente enterrada. A América Latina se integrou ao resto do planeta por meio de seus escritores") (id, p. 9) ;

- fazer uso de uma linguagem não experimental (“Em todas essas his-

que votou em Isabel Allende para o Prêmio Nacional de Literatura do Chile: "Levado a escolhar entre a frigideira e o fogo (os candidatos eram Allende, Skármeta e Teitebolim), escolho Isabel Allende. Seu glamour de sulamericana na Califórnia, suas imitações de García Márquez, sua inegável valentia, seu exercício da literatura que vai do kitsch ao patético e que de algum modo a torna semelhante a uma versão criolla e politicamente correta da autora do Vale das bonecas, produz um resultado, ainda que possa parecer improvável, bem superior à literatura de funcionários natos de Skármeta e Teitelboim” (Bolaño, 2002, p. 102) (tradução minha). 
tórias, a preocupação com uma linguagem eficaz e com a funcionalidade da construção é evidente) (id., p. 10) (tradução minha);

- abrir mão de experimentalismos formais ("nessas histórias a forma é muitas vezes invisível e, assim, perfeitamente identificada com personagens e seus avatares, atingindo a inteligência e sensibilidade do leitor" (id., ibid.).

É sumamente interessante como Vargas Llosa assume o lugar de escritor consagrado, da geração do boom e, a partir daí, proclama o quanto a nova geração é diferente, o quanto ela se opõe ao boom. Termina por anunciá-la como uma espécie de massa indefinível, cujo único traço comum é a negação do boom. Como se vê, o princípio é o da não-definição, mas uma não-definição que dá mostras de estar definindo. Ao mesmo tempo, a enumeração do autor peruano reforça e atualiza a vigência dos supostos preceitos do boom como paradigma, como totem.

Ao texto de Vargas Llosa, segue-se um texto de apresentação dos organizadores Guerrero e Iwasaki - sob o sugestivo nome "Un nouveau siècle, une nouvelle géneration" -, o qual opta pela inércia, aceitando de modo subjacente a premissa de que os cortes estéticos se dão ao sabor do avanço dos anos. Assim é que surge a geração nascida nos anos 1960 que ocupa o livro em sua totalidade. Autores em torno dos quarenta anos de idade que nasceram, segundo lembram os organizadores, no momento tornado mítico em que Jorge Luis Borges recebe das mãos dos "trois principaux éditeurs européens" (Claude Gallimard, Giulio Einaudi e Carlos Barral) o Prêmio Fomentor de 1961. As referências ao boom seguem aparecendo, como uma sorte de legitimação desta safra de herdeiros daquela tradição.

Dentre as demais coincidências apontadas pelos organizadores da antologia, que ajudam a traçar seu perfil, estão:

- a participação da maior parte dos autores da antologia em pelo menos um dos congressos de escritores latino-americanos ocorridos na Europa ao longo dos anos 1990 e 2000;

- a participação em antologias de literatura latino-americana, principalmente espanholas e norteamericanas;

- quanto à temática e às inquietações daquele grupo de escritores, a superação de questões como "a identidade latino-americana" e "a revolução":

As obsessões de idade da nação e as identidades se tornam sujeitos maleáveis ou objetos de escárnio e paródia - para além do que está acontecendo hoje em vários países europeus, onde tem havido um ressurgimento do nacionalismo perturbador. (id., 2010, p. 19) 
Ou seja, os jovens escritores são despolitizados - a se considerarem os paradigmas dos anos 1970 - são filhos do boom e o renegam; antes preferem participar de congressos de escritores no primeiro mundo. Assim ficam definidos os embaixadores da "nova geração" latino-americana na Europa, no critério de Guerrero e Iwasaki.

Quem se detiver a pensar no que propõem as duas apresentações terá a impressão de que algo vai mal, talvez não nos critérios de seleção dos editores da Gallimard - posto que há inegavelmente escritores muito bons na antologia -, mas na reflexão crítica sobre o que se escreve e, consequentemente, no que fica de fora da antologia.

O prefácio de Luis Gusmán a Os outros evidencia uma quebra em relação a este modelo de ordenação, embora guarde em comum com ele o princípio da indefinição. Trata-se nele de uma indefinição tomada como pressuposto. O organizador também cita Borges logo de início. No entanto, o faz de modo muito mais ambíguo, e embora reconheça seu lugar central no cânone, admite possibilidades outras, ademais do parricídio insinuado por Guerrero e Iwasaki:

Nós tivemos um milagre chamado Borges e qualquer um de nós tem que passar de uma maneira ou de outra - para usar a frase do escritor Rodolfo Fogwill - por essa aduana literária chamada Borges. Então alguns escritores creem que têm isenção de impostos, outros contrabandeiam, alguns apelam para o passaporte de diplomata, os mais ousados pretendem cruzar a fronteira comparando Borges com outros escritores. (Gusmán, 2010, p. 9)

E já no fragmento acima se mostra a particularidade do trabalho de Gusmán, seu mapeamento dá-se por uma perspectiva que privilegia a escritura. Sua posição como antologista é delicada, pois abre mão das certezas e chega a definir a literatura argentina como um "animal vivo", "um guincho" e a própria antologia como uma tentativa de indicar "alguma pista sobre a literatura argentina". É preciso dizer, portanto, que o fenômeno literário precede o advento da antologia, de maneira caótica, inorganizável, e da mesma maneira ordenada e geracional tal como o concebiam Guerrero e Iwasaki. Trata-se de antologizar um movimento, uma série de escritas vivas, não formáveis como geração:

Referir-me a cada texto publicado seria, além de inútil, reduzir a leitura ao método do catálogo; é por isso que o representativo não passa por um aspecto geracional. Há nessa antologia autores de todas as idades. Não só idade humana; não só idade de publicação; não só idade de leitura; mas idade de escritura. E isso, como se diz na brincadeira infantil, não tem idade. (id., p. 13) 
A partir desta disposição, aparentemente antiantológica, foi possível para Gusmán mostrar a presença de elementos estrangeiros e diaspóricos nos textos selecionados: autores estrangeiros que escrevem em espanhol, argentinos que escrevem como estrangeiros, temas estrangeiros, formas estrangeiras, o tema da migração etc., ao mesmo tempo em que uma unidade estilística fugidia, que não se deixa apreender por categorias, mas tão somente sob a metáfora "Os outros". Não houve, tampouco, o recurso à realidade sociohistórica para justificar a multiplicidade de elementos estrangeiros na antologia. O caráter de errância e de diáspora é atribuído não aos trânsitos de pessoas, mas aos próprios trânsitos que a escrita implica e coloca em cena:

O que há de representativo nesta antologia é o seu caráter de diáspora. Dispersão que não é preciso atribuir nem à política, nem à globalização. Há uma forma de literatura que não necessariamente está acompanhada do corpo do escritor. Apesar de o mercado e a exigência midiática tornarem cada vez mais indissociável a relação entre o livro como objeto e o corpo do escritor. (id., p. 11)

Se é a escrita o que Gusmán privilegia em sua seleção, por outro lado, a posição do artista, segundo ele, não é mais aquela das vanguardas. $\mathrm{O}$ manifesto, ou mesmo o discurso sobre a própria obra é posto em suspensão. $\mathrm{O}$ antologista proclama a impossibilidade de o autor vir a falar com propriedade acerca de sua própria obra, de vendê-la por seu valor de face: Não há mais viagem ao centro da Terra sem o romance de Verne. Há buraco negro. A viagem é outra. O ponto de partida não garante o ponto de chegada. Para além das intenções que levam cada escritor a se posicionar a respeito de sua própria literatura. (id., ibid.)

Neste panorama em que tudo é incerteza, o antologista propõe ordenar os textos como se compusessem uma intriga; e para tanto estabelece analogias entre alguns deles, conferindo-lhes caráter de continuidade - e uma fugidia ilusão de unidade - como numa trama de Agatha Christie. Desta forma, o prefácio serve como uma possibilidade de ordenar os textos autônomos. Tal procedimento atípico difere radicalmente do adotado pela Gallimard, por permitir incluir elementos anômalos e exorbitantes. Ter-se demitido do critério estrito, quase científico, permite a Gusmán agrupar autores diversos, que possam ter afinidades sutis na escrita, que não as de idade, lugar de nascimento ou poética.

Fazer uma antologia, para Gusmán, parece ser o mesmo que apostar e dar tiros no escuro - tal qual o detetive que blefa diante de um ponto cego. Que um ponto cego possa produzir uma antologia, isto sim é curioso. 
Ao confrontar o prefácio de Gusmán ao de Vargas Llosa - embora este último não fosse antologista e sim um apresentador da geração - chama a atenção como ambos os romancistas falam a partir de lugares diferentes. Vargas Llosa, como o escritor já estabelecido, que vê um movimento indefinível que se difere de sua própria escrita, e ao qual define como uma extensão dela, por negá-la. Luis Gusmán enuncia-se como parte de uma escrita indefinível, não catalogável; e embora busque ordenar a prosa de um país, o faz a partir da perspectiva da diáspora.

Se algo resta em comum entre as apresentações de Gusmán e a de Guerrero e Iwasaki é a percepção de que o conceito de nacionalidade parece algo superado na América Latina. Isto produziria uma pergunta, talvez sem resposta possível de imediato: se a nacionalidade entrou em crise, qual o sentido de seguir fazendo antologias? A antologia parte do princípio mesmo de que algo pode ganhar corpo; seja um corpo existente de antemão - como o defendem Guerrero e Iwasaki - seja um corpo forjado para entreter o leitor, como sugere Gusmán.

É possível lançar mão de uma hipótese de que são as antologias que dão ao leitor a ilusão da existência literária em nível nacional ou continental. São estas antologias, em suma, que ajudam a sustentar uma suposta nacionalidade ou novidade literária, como se ocupassem o lugar do manifesto literário, em sua natureza de postular qual a arte nova e legítima. Seja para afirmar uma estética - a da dispersão, como o quer Gusmán - ou para lançar editorialmente novos autores.

Parece ser este, com algumas mediações, o papel do antologista segundo o entende Stéphane Chao, em seu prefácio à Antologia Pan-americana. Diz ele: "é inegável que as sucessivas antologias atestam uma história da leitura, uma vez que estas não são, enquanto seleção de textos, ato de escrita, mas obra de leitor" (Chao, 2010, p. 14).

Pode-se abrir então o questionamento sobre o que pode significar estar numa antologia. Ao comentar o poema de Borges, que ocupa a posição de epígrafe a este artigo, Roberto Bolaño (1999), em entrevista a Cristián Warnken, discorda do entrevistador - como muitas vezes acontecera naquele encontro. Para Bolaño, chegar a uma antologia poderia ser considerado um privilégio, porque já era uma forma menos severa do esquecimento; dizia isso ao se lembrar que a antologia a que se referia o texto de Borges era de poetas ingleses de séculos idos, que já haviam sobrevivido ao completo aniquilamento.

O fato é que o lugar do escritor selecionado numa antologia parece ser algo incômodo: salvou-se de aniquilamento, mas está aquém da consagração. Ora, nem tudo é "antológico" nas antologias de contemporâneos, 
há aqueles que constam na antologia para uma certa forma de figuração, para conferir cor local à coleção ou, no limite, para, num exercício de engenho ocasional, confirmar a maestria dos outros.

Pode-se entender a antologia dos "novos" como o lugar do escritor menor e promissor, que pode vingar ou que pode simplesmente manterse no lugar de "autor menor da antologia". Vejamos, em Os outros não está Ricardo Piglia, como não está também o próprio Gusmán; ali figuram tanto os jovens escritores, como Florencia Abbate quanto os que já se estabeleceram como outsiders, como é o caso do septuagenário Luis Tedesco.

Em Les bonnes nouvelles é o próprio corte temporal (autores nascidos após 1960) que de um golpe exclui nomes como Roberto Bolaño (19532003), Juan Villoro (1956-), Alan Pauls (1959-) e, mais uma vez, Ricardo Piglia (1940-), e estabelece a coletânea como lugar de autores menores, que podem crescer ou não.

Deparar-se com uma antologia de contemporâneos suscita sempre a pergunta acerca de como se escrever a "nova" literatura. Entretanto, como bem o indica Gusmán, já é possível, passados cem anos das vanguardas europeias, olhar para a literatura que se produz contemporaneamente sem procurar nela a novidade. É quase uma ilusão juvenil considerar que aquilo que se estabelece cronologicamente como sendo uma geração representa uma forma diversa de escrita e de relação com o texto literário.

O interessante de Les bonnes nouvelles é que, ao optar pelo corte geracional, de modo quase acrítico, traz um panorama da pampa desértica das letras americanas onde encalhou a arca de Noé. Se tomarmos o exemplo dos autores cubanos, há um interessante espectro tipológico dos textos: Há um texto ameno, de Karla Suárez, "La collectionneuse", que faria sucesso num magazine; uma jovem autora que dá mostras de poder ir além da escrita pessoal, Ena Lucía Portela (e que mesmo na escrita pessoal é bem mais interessante que Yoani Sánchez); uma poderosa reescritura do conto "A carne", de Virgilio Piñera, por Ronaldo Menéndez, que resulta, agora sim, em um texto antológico; e finalmente, há uma narrativa que retoma a boa prosa oral, em "La requête d'Ochún", no bairro chinês da Havana, escrita por Antonio José Ponte. Assim, recobrem-se tanto a distração pueril, a narrativa oral, a escrita adolescente e o diálogo com a tradição nacional.

Talvez o grande mérito de Les bonnes nouvelles seja desmentir as palavras de um de seus organizadores, Guerrero, ao mostrar empiricamente como os critérios de leitura e seleção mostram muito mais do antologista do que da literatura de seu tempo, e como o julgamento crítico e literário segue vigente, a despeito dos critérios mercadológicos. Mostra, enfim, 
como nem todas nouvelles são boas, mas sempre elucidativas da posição do leitor e organizador.

\section{Referências bibliográficas}

BOLAÑO, Roberto (1999). La belleza del pensar. Entrevista a Cristián Warnken. Santiago: UC Televisión, 1999. Disponível em <http://garciamadero.blogspot.com/2008/05/roberto-bolao-en-la-belleza-de-pensar.html>. Acesso em: 12 de março de 2011)

(2002). "Sobre literatura, el premio nacional de literatura y los raros consuelos del oficio". In: Entre paréntesis. Barcelona: Anagrama, 2004. p. 102-5. BORGES, Jorge Luis (1992). "A um poeta menor da antologia". Trad. Leonor Scliar-Cabral. In: Obras completas. São Paulo: Ed. Globo. v. 2.

CHAO, Stéphane (2010). Antologia pan-americana: 48 contos contemporâneos do nosso continente. Rio de Janeiro: Record.

DONOSO, José (1987) [1972]. Historia personal del "boom". Santiago: Andrés Bello.

GUERRERO, Gustavo e IWASAKI, Fernando (Orgs.) (2010). Les bonnes nouvelles de l'Amérique latine: anthologie de la nouvelle latino-américaine contemporaine. Paris: Gallimard.

GUERRERO, Gustavo (2009). “Crítica del panorama”. In: Letras Libres. Madri: Vuelta. Disponível em: <http://www.letraslibres.com/index. php?art=13872>. Acesso em: 6 de janeiro de 2011.

GUSMÁN, Luis (Org.) (2010). Os outros: antologia de narrativa argentina contemporânea. São Paulo: Iluminuras.

MORGADO, Marcia (2000). "Literatura para curar el asma. Una entrevista con Mayra Santos Febres". In: The Barcelona Review. Revista Internacional de Narrativa Breve Contemporánea. n. 17, março-abril. Disponível em: <http:// barcelonareview.com/17/s_ent_msf.htm>. Acesso em: 4 de janeiro de 2011.

Recebido em maio de 2011.

Aprovado em julho de 2011.

\section{resumolabstract}

\section{Promessas antológicas: o conto latino-americano contemporâneo a partir} de algumas antologias

Wilson Alves-Bezerra

$\mathrm{O}$ que as antologias contemporâneas de literaturas americanas têm a mostrar sobre as formas de ler, organizar e selecionar a narrativa curta contemporânea da América Latina? Por meio de algumas considerações sobre três antologias do gênero recentemente publicadas - Antologia pan-americana; Os outros: antologia de 
Wilson Alves-Bezerra

narrativa argentina contemporânea; Les bonnes nouvelles de l'Amérique latine - serão problematizadas algumas questões relativas ao lugar do mercado, os critérios utilizados pelos antologistas e a vigência de visões calcificadas sobre a produção continental, como o boom literário latino-americano dos anos 1950 e o realismo mágico. Ao comentar os critérios adotados pelas antologias será possível refletir sobre o gênero em nosso contexto atual.

Palavras-chave: literatura latino-americana, literatura contemporânea, literatura e mercado, antologia, conto contemporâneo, boom latino-americano

Anthological promises: the contemporary Latin American short story from a few anthologies

Wilson Alves-Bezerra

What do contemporary anthologies of Latin American literature portray in regards to the ways of reading, organizing and selecting the short contemporary narratives of Latin America? Some issues will be approached, grounded in considerations made over three recently published anthologies within this genre - Antologia pan-americana; Os outros: antologia de narrativa argentina contemporânea; Les bonnes nouvelles de l'Amérique latine. The issues are related to the market influences, the criteria employed by anthologists and the endurance of fossilized views on the continental production such as the boom of Latin American Literature from the fifties and the magical realism. Addressing, mainly, the criteria adopted by the anthology of Gallimard Publisher will yield reflection over the genre in our current context.

Key words: latin-american literature, contemporary literature, literature and market, anthology, contemporary short stories, latin american boom

Wilson Alves-Bezerra - "Promessas antológicas: o conto latino-americano contemporâneo a partir de algumas antologias". Estudos de Literatura Brasileira Contemporânea, n. 38. Brasília, julho-dezembro de 2011, p. 61-72.

72 estudos de literatura brasileira contemporânea, n.38, jul./dez. 2011, p. 61-72 